his most suggestive and instructive address. I should hesitate in thus seeking, by my feeble pen, to support his views did I not suspect that this curious horror of loss of blood in these days of "bloodless surgery" has reached such a point that operators exist who have performed every brilliant feat in the wide range of surgery, and yet who have hitherto shrunk from performing the simple operation of venesection. A most remarkable instance corroborative of this suspicion comes to my recollection as I write. Some time ago I had a patient under my care suffering under urgent symptoms of impending suffocation consequent upon acute inflammation of the upper portion of the larynx and adjacent parts. A consultation was held of surgeons of great operative ability and also of great experience. All were willing to sanction my opening the trachea, but not one would sanction my opening a vein at the bend of the elbow. However, not being as thoroughly impressed as perhaps I should have been with the importance of the doctrine of the change of type in disease, $I$ insisted upon bleeding my patient, and never shall I forget his sense of relief as ounce after ounce escaped into the cup, until at last he exclaimed, "Thank God, I can breathe now as well as ever I did"; and from that out his convalescence was uninterrupted. Between the times to which Sir James Paget alluded and the present day there was a transition period, during which cupping was in vogue. In these days were famous the names of Mapleson, Betts, Minos, and many others, who made a handsome income by the performance of this operation - an operation, by the way, requiring for its skilful performance such an amount of dexterity as could only be acquired by practice, that the army medical authorities of the day insisted upon a!l assistant-surgeons entering the service producing a certificate of proficiency in cupping, either in London, as well as I remember, from Mapleson, or in Dublin from myself. It is unnecessary for me here to $d$ well upon the amount of relief I have seen following the abstraction of blood after this fashion; suffice it to say that nowadays we have changed all that, and no one can deny that in this respect tempora mutantur; whether the rest of the line, nos et mutamur in illis, be equally true is, in my opinion, however, open to serious discussion. This transition period has also come to a termination, at all events for the present; and now, at last, we find ourselves arrived at the age of bloodless surgery-a mode of procedure upon which it is not my intention at present to comment, but with respect to which I may incidentally remark that my experience, at all events in amputations, does not lead me to be quite as much enamoured of it as seem to be some of my surgical brethren. I am, Sir, your obedient servant,

RaWdon Macnamara, Surgeon to the Meath Hospital, \&c.

Stephen's-green, Dublin, Sept. 7th, 1874.

\section{THE NEWCASTLE INFIRMARY.}

To the Editor of The Lancer.

SIR,-Having recently been engaged in the investigation of some of the causes of death after severe operations, I was led to examine into the statistics of mortality from such causes in our own Infirmary. The result of these investigations has revealed such an unusually high rate of mortality that I feel compelled, in the cause of humanity and science, to bring the facts before the public, in order that they may receive that thorough ventilation which the importance of the circumstances demands, and that some effectual steps may be taken to check or in some way mitigate their very serious effects. That the facts which $I$ shall bring before you should have escaped public recognition so long I can only attribute to the apathy of the governors and the laissez aller manner in which most of our charitable institutions are conducted. To quote from a leader of THE LANCET written so long ago as the year 1830: "The generality of persons who contribute to the support of our hospitals appear to believe that their only duty consists in throwing a certain sum of money into the hospital funds. ...... Shame on the idle and thoughtless subscribers! they augment the evils which they intend to subvert." Unwilling to trespass uselessly upon your space or to trouble you with digressions, I shall proceed to deal immediately with facts, giving you to understand that all figures are drawn from the published reports issued by the infirmary authoritios, and are within the reach of every governor of the infirmary.

A glance at the accompanying table will show that I have tabulated the principal operations that have been performed in the infirmary during the last five jears, classified them, and ascertained their percentage of deaths. These $I$ have compared with well-known and authenticated statistics of other places, and the following is the result:-

That during the last five years, of 128 persons who have been subjected to one of the major amputations in the Newcastle Infirmary, 62 have died; being a mortality equal to 48.4 , or one person died in every $2 \cdot 06$. Thus one-half nearly of all the major amputations have died. This rate of mortality is very painful to contemplate; let us contrast it with other statistics. Mr. Callendar, in the year 1869 (St. Bartholomew's Hospital Reports), collected some statistics which are well authenticated, and have been accepted by the profession as reliable, and he found that in ten provincial hospitals, having a number of beds from 150 to 270 (in other words, corresponding to our own), the mortality of all amputations was equal to $19 \cdot 23$, or that 1 in 5.2 patients died. Compare this-

$$
\begin{array}{llll}
\text { Newcastle Infirmary _.... } & 48.4 \text { or } 1 \text { in } 2.06 \\
\text { Mr. Callendar's statistics ... } & 19.23 \text { or } 1 \text { in } 5 \cdot 2
\end{array}
$$

Lest some should feel inclined to think that the comparison between two sets of statistics alone is not quite fair, let us contrast our rate of mortality with that published this year by Mr. Erichsen.* This rate of mortality, after all amputations, amounts to 26 per cent. With this, however, he is not satisfied, and makes the following comments:- "Now a general mortality for many years of 24 to 26 per cent. in all major amputations of the limbs for all cases may be considered as a very satisfactory result, although there can be no question that it is one that admits, and that ought to be susceptible, of very great improvement." Now, if this is the view of one of our most eminent surgeons upon a mortality of 26 per cent., what must our needs and susceptibilities be with a mortality of 48 per cent., or not far short of double?

It would occupy far too much space were I to attempt to contrast the mortality of each separate kind of operation and make comments thereon. The table which I have drawn up gives sufficient information to show that in all cases they are excessively high, and in the right-hand column is given the percentage of mortality for the same kind of operation based on a calculation of averages obtained from fifty different provincial hospitals. $\dagger$

The table of excision of the knee-joint is most unfarourable as far as it goes, showing a mortality of 80 per cent.s as contrasted with 26 per cent., which is the percentage upon a large number of cases collected by Mr. Swain. Upon the table of herniotomy cases I will make no comment, as but few reliable statistics exist for comparison. the rate of mortality is, however, unquestionably high.

What specially strikes a professional eye, and points out most forcibly the unhealthy condition of the hospital, is the large rates of mortality for the smaller operations. Thus a mortality of 20 per cent. for amputations of the forearm is a thing almost unheard of ; and when this is supplemented by a mortality of 17 per cent. on partial amputations of the hand and foot-a class of cases in which a death should very rarely occur, - the evidence in favour of the insanitary condition of our building is conclusive.

In entering upon this criticism of the statistics of our infirmary I have had to contend with serious difficulties, because the reports throughout are so meagre and so unscientifically compiled as to be all but valueless for any but the most superficial examination. This is much to be regretted, as each year the importance of well-compiled and accurate statistics is becoming more and more recognised, and has led, in most well-conducted infirmaries, to the appointment of a special salaried officer, whose sole duty it is to tabulate and analyse the cases, and place them in a form. where facts speak for themselves. That our own institution, which boasts of a school and aspires to a scientific reputation, should so long remain behind, is surely a disgrace.

Let me point out some of the defects in this table. According to last year's report there are four cases of double amputation; but whether of two arms, two legs, or one arm

* Erichsen on Hospitalism

$\dagger$ St, Bartholomew's Hospital Reports, vol, $\mathbf{}$. 
and a leg, it does not say. Again, in some of them, we find hydrocele, cancer of the lip, harelip, and fistula lumped together. In the name of common sense, what connexion can there be between a harelip and a fistula, a hydrocele and a cancer of the lip?-and how is it possikle to recognise to which group of cases the death belongs where such a classification is made? Despite the great improvement that has been made in the ophthalmic department, no better information is vouchsafed to us than that twenty-four operations were performed. It will be gratifying to learn that all of these recovered; but whether they recovered with their sight! or their lives! is left a matter of conjecture. Another feature in this wonderful table I cannot pass over: it alludes to a class of operations which are not named, but which pass under the vague category of " other operations." During the last five years no less than twenty persons have died whilst undergoing the process of "other. operating"; and I cannot but think that, in a scientific point of view, it would be desirable to know what these persons were subjected to.

Having thus shown the difficulties which surround the investigation of these statistics, I pass on to the examination of another class of cases. During the five years end. ing March, 1874, 115 cases of fracture have died in the infirmary. Now, our report makes no separation of simple and compound fractures; but as we know for a fact that it is a very rare event for a person to die of a simple fracture, we may take it as conclusive that these 115 cases relate to

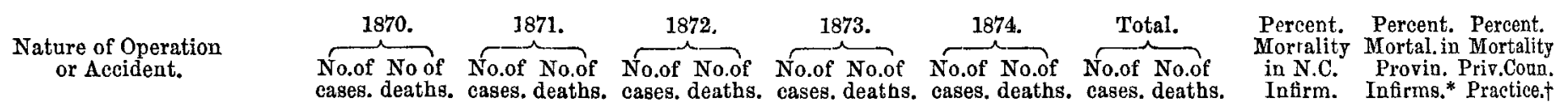

(18. deaths. cases. deaths. Infirm. Infirms. "Practicet

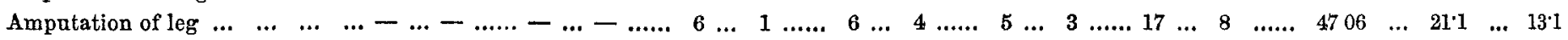

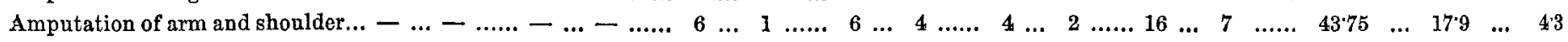

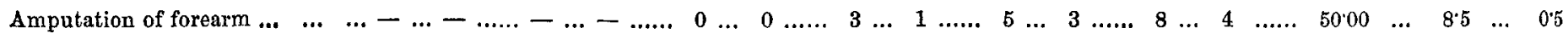

Amputation at hip-joint $\ldots \ldots-\ldots-\ldots \ldots-\ldots-\ldots \ldots 1 \ldots 1 \ldots \ldots-\ldots-\ldots \ldots-\ldots-\ldots \ldots 1 \ldots 1 \ldots \ldots 10000 \ldots-\ldots-\ldots-$

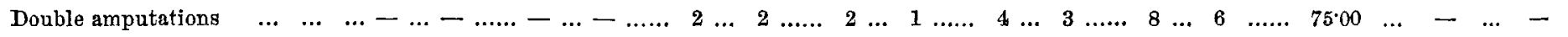

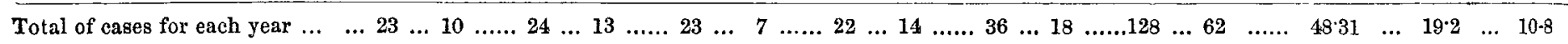

\begin{tabular}{lllllllllllllll}
\hline Rates of mortality for each year $\ldots$ & 43.5 & $\ldots \ldots$ & 5417 & $\ldots \ldots$ & 30.43 & $\ldots \ldots$ & 6363 & $\ldots \ldots$ & 60.00 & $\ldots \ldots$ & $-\ldots$ & $-\ldots \ldots$ & - & $\ldots$
\end{tabular}

Partial amputat, of handand fot 40

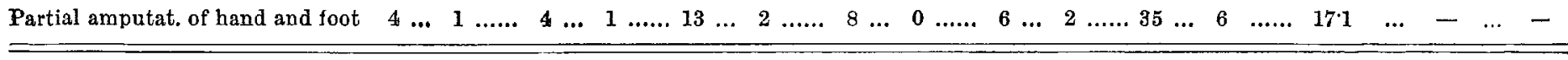

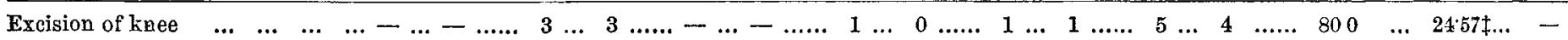

Strangulated hernia

$\begin{array}{lllllllllllllllllllllllllll}6 & \ldots & 2 & \ldots & \ldots & \ldots & \ldots & 0 & \ldots & \ldots & \ldots & \ldots & 2 & \ldots & 1 & \ldots & 0 & \ldots & 5 & \ldots & 3 & \ldots & 18 & \ldots & 7 & \ldots \ldots & 38\end{array}$

* Mr. Callender, St. Bartholomew's Hospital Reports, vol. v., p. 262.

$\dagger$ Ibid.

$\ddagger$ Holmes's System of Surgery, vol. v., p. 706.

compound fractures. This will give us an average of 23 deaths each year from compound fractures alone, admitting (and I think we shall not be far from the facts) that an average of 1 compound fracture is treated per week in the infirmary; we should then have 52 cases, with 23 deathsa proportion of nearly 50 per cent., or nearly one death to every recovery. I have no very reliable statistics with which to compare these results, but any experienced surgeon will recognise their truly startling proportions.

But to come to our conclusions. What does all this prove? It proves incontestably, undeniably, and irresistibly that our present infirmary is not fit for the reception of severe accidents, or for the performance of severe operations. It proves that, with all skill and care, and the exercise of all precautions, its old walls are so saturated with hospital miasm that nothing can rescue its victims when they are once surrounded by them. It proves that in bringing a patient to the infirmary, and subjecting him to an amputation, you are subjecting him to a risk almost three times as great as is necessary. Is this humanity? Is this the object of our lavish and abundant charity? Is this the crowning point of our improvements in surgery and bygiene? But what are the steps that should be taken? Surely the condition of affairs is one that admits of no temporising or delay. It is obviously a sutire alike upon charity, humanity, and science to place our sick and trusting poor under conditions which, instead of conducing to their cure, hasten their destruction.

I am, Sir, your obedient servant, Chrtstopher S. Jeaffreson, F.R.C.S.E.,

$$
\begin{array}{r}
\text { Newcastle, Sept. 1874. Surgeon to the Eye Infirmary } \\
\text { Children's Hospital. }
\end{array}
$$

\section{MODE OF ORIGIN OF ANIMAL HEAT.}

\section{To the Editor of THE LANCET.}

$\mathrm{SrR}_{3}, \mathrm{I}$ desire to call attention to a mode of origin of animal heat which appears to me to be an important one, and which, so far as I have been able to discover, does not seem to have received the attention it deserves.

In Carpenter's Physiology (seventh edition, pp. 486 and 492), the sources of heat produced in an animal are thus given :-(1) Metamorphosis and oxidation of its own tissue ; (2) oxidation of certain "heat-giving" foods; (3) a certain modifying or even originating influence of the nervous system is recognised, acting probably not always in the same way, but the remote source being still regarded as always chemical. Thus, no mention is made of the beat-producing effect of the retardation of the blood-strean in the capillaries, nor have I found this noticed in other works on the subject. Such a source of heat appears at first sight to be trivial, but will be found on calculation to be by no means unimportant. The remote source will no doubt still be chemical.

The momentum acquired by the blood from the contraction of the ventricles of the heart is almost entirely lost after passage through the capillaries, no doubt chiefly owing to the immense area of resistance there afforded. Volkmann (Carpenter's Physiology, p. 291) gives the pressure of the blood in one of the peripheral arteries of a calf as equal to 146 millimetres of mercury, whereas in the corresponding peripheral vein it is reduced to 27.5 millimetres. We now know that though this momentum has disappeared as such, its equivalent of force still exists in another form-that the movement has only passed from the mass to its component molecules, and become heat. There appears to be no escape from the conclusion that the whole of the mechanical energy originating in the contraction of the ventricles of the heart $s$ converted into heat within the body, and that this conversion principally takes place in the capillaries.

The mechanical force of both ventricles of the human heart has been estimated by Ranke (Carpenter's Physiology, p. 265) at 86,700 kilogrammeters, or 623,621 footpounds, in twenty-four hours. Taking Joule's equivalent (772 foot-pounds equal heat necessary to raise 1 pound of water $1^{\circ} \mathrm{F}$. in temperature), it will be found that the whole amount of heat which this represents is equal to that required to raise about $4 \frac{1}{2}$ pounds of water from freezing to boiling-beat, or to about one-tenth of the whole heat produced in the body. (See Carpenter's Physiology, p. 491.)

It is possible that this mode of the production of heat may have important bearings upon the solution of questions such as the relation subsisting between cardiac, arterial, and capillary tone and temperature; certain recently discovered paradoxical effects on temperature of prolonged immersions of healthy persons in cold water; the effects of large doses of alcohol on temperature, \&c.

\section{I am, Sir, yours truly,}

Chas. A. Rayne, M.B. Lond.

The Radcliffe Infirmary, Oxford, Sept. 12th, 1874. 